\title{
Correspondence
}

Irish Journal of Psychological Medicine, 32 (2015).

doi:10.1017/ipm.2014.94

\section{Regarding: The impact of a change in prescribing policy on antipsychotic prescribing in a general adult psychiatric hospital}

\section{Dear Editor,}

We read with interest the recent audit by Kelly et al. on the favourable impact of local policy change on prescribing of multiple antipsychotic medications (Kelly et al. 2014). It has clearly confirmed that adoption of the new antipsychotic prescribing policy has resulted in a positive impact on prescribing multiple antipsychotics. The percentage of patients prescribed multiple antipsychotics has gone down significantly from $28 \%$ to $16 \%$ (significantly better than a reduction in prescribing multiple antipsychotics from $43 \%$ to $39 \%$ reported in a similar large-scale UK audit; Paton et al. 2008). The latter figure provided by Dr Kelly and his colleagues (i.e. 16\%) is comparable with the $14.4 \%$ figure found in a survey of prescribing multiple antipsychotics for patients with schizophrenia in the United States (Edlinger et al. 2005) and the $15.9 \%$ figure reported in a similar English survey (Patel et al. 2014). A recent French study reported a staggering $49.3 \%$ rate of prescribing for multiple antipsychotics across all general hospitals in France (Bret et al. 2009).

However, in the reported results of Kelly et al.'s audit, we could not identify the route of administration of antipsychotics. Practically speaking, we do prescribe injectable long-acting antipsychotics to a large number of patients. According to National Institute for Health and Clinical Excellence (NICE) Guidance, long-acting antipsychotics should be monitored the same way like oral antipsychotic medications: 'take into account the same criteria recommended for the use of oral antipsychotic medication, particularly in relation to the risks and benefits of the drug regimen' (NICE, 2014). In Kelly et al.'s study, the proportion of patients on longacting injectable antipsychotics was not provided. The only exclusion criterion was being on clozapine augmented with regularly prescribed antipsychotics. This led to exclusion of three patients.

Very little, if any, research has evaluated the rate of co-prescription of oral and depot antipsychotics. In 2002, in an investigation carried out by Tylor et al. (2002), 15 patients were identified to be on combined depot and oral antipsychotics. A more recent audit identified 43 of patients on combined depot and oral antipsychotics; likely to be chlorpromazine or haloperidol prescribed for agitation or insomnia (Rajan \& Clarke, 2013).
Depot injections are licensed for treatment of psychotic disorders. There are eight depot preparations listed in the most recent BNF (The Joint Formulary Committee, 2014). A couple of difficulties may have led to underinvestigation of depot preparation in the range of studies aimed at estimating the extent of antipsychotics polypharmacy. First, the slow-release nature of longacting antipsychotics can make it hard to calculate the total daily antipsychotic dose percentage. Second, the section for prescribing the depot preparation in the medication kardex is often at the back of the chart or at the bottom of a page far away from the regular prescriptions section. This can lead to easy omission, specifically if it is not borne in mind while collecting the data on antipsychotic polypharmacy.

A particular clinical conundrum is when patients who are established on maintenance depot antipsychotics become acutely unwell. It is almost always tempting to commence some oral antipsychotic medication that is intended to control the acute episode of behavioural disturbance. Despite the intention to be prescribed for short-term use, patients often end up being on combined oral and depot antipsychotics. Do the authors agree that such episodic behavioural disturbances can be a major route to antipsychotic polypharmacy? Can they provide any guidance on how to manage such episodes without subjecting patients to the risk of exceeding the daily antipsychotic dose limit?

\section{References}

Bret P, Bret MC, Queuille E (2009). Enquête de pratiques de prescription des antipsychotiques dans 13 centres hospitaliers du réseau PIC [Prescribing patterns of antipsychotics in 13 French psychiatric hospitals]. Encephale 35, 129-138.

Edlinger M, Hausmann A, Kemmler G, Kurz M, Kurzthaler I, Walch T, Walpoth M, Fleischhacker WW (2005). Trends in the pharmacological treatment of patients with schizophrenia over a 12 year observation period. Schizophrenia Research 77, 25-34.

The Joint Formulary Committee (2014). British National Formulary, 67th edn. BMJ Group and Royal Pharmaceutical Society Publishing: London 249pp.

Kelly J, Kelly F, Santlal K, O'Ceallaigh S (2014). The impact of a change in prescribing policy on antipsychotic prescribing in a general adult psychiatric hospital. Irish Journal of Psychological Medicine 31, 167-173.

National Institute for Health and Clinical Excellence (NICE) (2014). Psychosis and schizophrenia in adults: treatment and management (NICE clinical guideline No. 178), section 1.5.6: Using depot/long-acting injectable antipsychotic medication, p. 32. Available online on http:/ /www.nice.org.uk/ guidance/cg178/resources/guidance-psychosis-andschizophrenia-in-adults-treatment-and-management-pdf (accessed on 6 January 2015). 
Patel MX, Bishara D, Jayakumar S, Zalewska K, Shiers D, Crawford MJ, Cooper SJ (2014). Quality of prescribing for schizophrenia: evidence from a national audit in England and Wales. European Neuropsychopharmacology 24, 499-509.

Paton C, Barnes TR, Cavanagh MR, Taylor D, Lelliott P, POMH-UK Project Team (2008). High-dose and combination antipsychotic prescribing in acute adult wards in the UK: the challenges posed by p.r.n. prescribing. British Journal of Psychiatry 192, 435-439.

Rajan L, Clarke I (2013). Audit of combination and high-dose antipsychotic treatment in the community. Psychiatric Bulletin 37, 302-307.
Tylor D, Mir S, Mace S (2002). Co-prescribing of atypical and typical antipsychotics - prescribing sequence and documented outcome. Psychiatric Bulletin 26, 170-172.

Mugtaba Osman $^{1}$ and MacDara McCauley ${ }^{2}$

${ }^{1}$ Senior Registrar General Adult Psychiatry, Graduate Statistician, and Clinical Tutor, St Birgid's Hospital, Co. Louth, Ireland (Email: mugtabasulman@yahoo.co.uk)

${ }^{2}$ Consultant Psychiatrist and Senior Clinical Lecturer, St Birgid's Hospital, Co. Louth, Ireland

First published online 19 January 2015 